Original Article

\title{
PRACTICES AND PERCEPTION OF NIGERIAN COMMUNITY PHARMACISTS TOWARDS ANTIMICROBIAL STEWARDSHIP PROGRAM
}

\author{
USMAN ABUBAKAR \\ 1Department of Pharmacy Practice, Kulliyah of Pharmacy, International Islamic University Malaysia, 25200, Kuantan, Pahang, Malaysia, \\ ${ }^{2}$ Pharmacy Department, Ibrahim Badamasi Babangida Specialist Hospital, Minna, Niger State, Nigeria \\ Email: pharmumma2@gmail.com
}

Received: 28 Nov 2019, Revised and Accepted: 12 Feb 2020

\section{ABSTRACT}

Objective: Community pharmacists have an important role in promoting the appropriate use of antibiotics. There is a paucity of data describing the contributions of community pharmacists in antimicrobial stewardship program (ASP) in Nigeria. This study evaluated the practices and perceptions of community pharmacists towards ASP.

Methods: This was a cross-sectional study conducted among community pharmacists in two cities in Northern Nigeria: Minna and Kaduna, using a 30-item validated and pre-tested questionnaire. Data collected between April and May 2019 and analyzed using SPSS version 23.

Results: Of 130 community pharmacists, 98 completed and returned the questionnaire (response rate: $75.3 \%$ ). More than 90\% strongly agreed/agreed that ASP is important to reduce inappropriate use of antibiotics and antibiotic resistance, improve patient's clinical outcomes. However, lack of training (56.1\%), lack of cooperation from physicians $(61.2 \%)$ and lack of access to patient records (66.8\%) were identified as barriers to community pharmacists' involvement in ASP. Overall, community pharmacists had good practices (median score: 3.5; IQR: 1-5) and positive perceptions (median score: 4.0; IQR: 3-5) towards ASP. Job status and dispensing antibiotics without prescription were significantly associated with practice, while age and job status were associated with perception towards ASP.

Conclusion: Community pharmacists demonstrated good practices and positive perceptions towards ASP. However, lack of training and lack of cooperation from prescribers limit their involvement in the program. Training of community pharmacists in antimicrobial stewardship and interprofessional collaboration are recommended.

Keywords: Community pharmacist, Practices, Perceptions, Antimicrobial stewardship, Antibiotics, Cross-sectional study, Nigeria

(C) 2020 The Authors. Published by Innovare Academic Sciences Pvt Ltd. This is an open access article under the CC BY license (http://creativecommons.org/licenses/by/4.0/) DOI: http://dx.doi.org/10.22159/ijpps.2020v12i4.36505. Journal homepage: https://innovareacademics.in/journals/index.php/ijpps

\section{INTRODUCTION}

The escalation of antibiotic resistance, coupled with the lack of new agents in the development pipeline, have caused an antibiotic crisis that threatens global health security [1]. Antibiotic resistance causes morbidity, mortality and huge economic loss [1-3]. Inappropriate use of antibiotics; in both community and hospital settings contributes to the emergence and spread of antibiotic resistance [1]. In community setting, illicit sale of antibiotics and self-medication are serious issues that affect antibiotic resistance. Population studies have shown that non-prescription use of antibiotics is higher in Africa compared to Europe, Asia and the Middle East [4]. The prevalence of non-prescription dispensing of antibiotics in community pharmacy is $62 \%$ [5]. Dispensing antibiotics without prescription poses a greater threat to antibiotic resistance compared to prescription use due to high rate of selection and dosing errors associated with the former [4]. In addition, non-prescription antibiotics are often used for the treatment of self-limiting illnesses, including upper respiratory tract infections [5].

In Nigeria, the inappropriate use of antibiotics in both hospital and community settings has been previously reported [6-8]. In addition, the prevalence of antibiotic resistance has increased in recent years [9]. Non-prescription dispensing and self-medication with antibiotics are common issues in Nigeria. A recent study revealed that more than two-thirds of community dwellers use antibiotics without a prescription [10]. Antibiotics mostly purchased from community pharmacy and patent medicine store $[11,12]$; and were commonly used for menstrual symptoms [11]; upper respiratory tract infections including sore throat, cough and cold [10] and gastrointestinal tract; urinary tract and skin infections [12]. Some of these illnesses are self-limiting and do not require an antibiotic. Also, non-prescription dispensing of antibiotics is associated with under-dosing [8], which leads to sub-therapeutic concentration and antibiotic resistance. Although, antibiotics are considered as prescription-only medicine in Nigeria, they are purchased by the public without a valid prescription due to weak law enforcement.

Antimicrobial stewardship (AMS) has become an important strategy in the fight against antibiotic resistance. Community pharmacists have an important role to play to promote and improve the appropriate use of antibiotics. In Australia, community pharmacists triage patients, recommend some over-the-counter or self-care therapy based on the patient's need and refer those with symptoms of an infection to a physician. In addition, they review antibiotic prescription prior to dispensing and educate patients regarding side effects and how to manage them when they occur [13]. In developing countries, there is paucity of data to describe the contribution of community pharmacists in AMS program. In Nigeria, hospital pharmacists participate in AMS program despite the absence of a formal AMS team in most hospitals [14], and their involvement in AMS has improved the appropriate use of antibiotics [15]. However, there is a lack of data describing the contributions of community pharmacists in AMS in the country. The objective of this study was to evaluate the practices and perceptions of community pharmacists towards AMS.

\section{MATERIALS AND METHODS}

\section{Methods}

\section{Study design and population}

A cross-sectional study was conducted among community pharmacists in two cities in Northern Nigeria: Minna and Kaduna, using a self-administered validated and pretested questionnaire between April and May 2019. The two cities were selected for convenience. Based on the 2006 national population census, Minna and Kaduna metropolis had an estimated population of over 350 
thousand and 760 thousand people, respectively. All the community pharmacists in the two cities were considered for inclusion, those who declined to participate, and patent medicine vendors were excluded from the study.

\section{Questionnaire design}

The questionnaire was developed in the English language by a clinical pharmacist who has expertise in AMS after the review of the previously published literatures [13, 16, 17]. Face and content validations were performed by two local community pharmacists to ensure that the questionnaire is comprehensible and relevant to the local setting. The questionnaire was revised based on the comments and suggestions of the reviewers. The final questionnaire consists of three sections and 30 items including demographic section (five items), and perceived importance of AMS (four items), and barriers (six items) and motivations (three items) of community pharmacists to participate in AMS. Perception was assessed using a 5-point Likert scale and was scored using 5 and 1 point for strongly agree and strongly disagree, respectively. The negative items were reversecoded. The third section had 12 items which assessed the practices of AMS among community pharmacists. The questionnaire was pretested among 12 community pharmacists and the Cronbach's alpha for perception and practice sections was 0.717 and 0.868, respectively.

\section{Data collection}

The investigator could not access the official list of community pharmacies in the two cities. Thus, a snowball sampling technique was used to identify all the community pharmacies in the two cities through their signboards on buildings or in the streets. The questionnaire was self-administered. In large community pharmacies with more than one pharmacists, all the pharmacists were invited to participate in the study. Participants were given the option to either complete the questionnaire on the spot or have the completed questionnaire picked up. The investigator visited nonrespondents to retrieve the completed questionnaires until the last day of the survey. A cover letter indicated that participation is voluntary and submission of response was considered as consent to participate in the survey.

\section{Ethical clearance}

This research was part of a project that evaluated illicit sale of antibiotics, and the practices and perceptions of hospital and community pharmacists toward ASP. The protocol for the project was reviewed and approved by the Health Research Ethics Committee of Ahmadu Bello University Teaching Hospital, Zaria (ABUTHZ/HREC/G22/2019).

\section{RESULTS}

\section{Characteristics of the community pharmacists}

Of the 152 community pharmacists approached, 22 declined to participate in the study. One hundred and thirty pharmacists received the questionnaire and 98 completed and returned their questionnaire corresponding to $75.3 \%$ response rate. Males constituted approximately two-third of the respondents. Community pharmacy owners and staff pharmacists represented $33.7 \%$ and $43.9 \%$ of the respondents, respectively. Most (49.0\%) of the respondents had less than $5 \mathrm{y}$ of community pharmacy work experience. Table 1 summarizes the characteristics of the respondents.

Table 1: Characteristics of the community pharmacists who participated in the study

\begin{tabular}{|c|c|c|}
\hline Variable & Frequency & Percentage \\
\hline \multicolumn{3}{|l|}{ Age (years)* } \\
\hline Less than 30 & 31 & 31.6 \\
\hline $31-40$ & 34 & 34.7 \\
\hline $41-50$ & 16 & 16.3 \\
\hline 51 and above & 15 & 15.3 \\
\hline \multicolumn{3}{|l|}{ Gender ${ }^{*}$} \\
\hline Male & 64 & 65.3 \\
\hline Female & 31 & 31.6 \\
\hline \multicolumn{3}{|c|}{ Highest professional qualification* } \\
\hline B. Pharm & 65 & 66.3 \\
\hline Masters & 16 & 16.3 \\
\hline $\mathrm{PhD}$ & 1 & 1.0 \\
\hline WAPCP fellowship & 11 & 11.2 \\
\hline \multicolumn{3}{|l|}{ Job status ${ }^{*}$} \\
\hline Pharmacy owner & 33 & 33.7 \\
\hline Pharmacy manager & 16 & 16.3 \\
\hline Staff pharmacist & 43 & 43.9 \\
\hline \multicolumn{3}{|l|}{ Years of experience* } \\
\hline Less than 5 & 48 & 49.0 \\
\hline $5-10$ & 14 & 14.3 \\
\hline 11 and above & 30 & 30.6 \\
\hline
\end{tabular}

*indicates missing data; WAPCP: West Africa Post-graduate College of Pharmacy Fellowship

\section{Perceptions of community pharmacists towards antimicrobial stewardship program}

Table 2 describes the perceptions of community pharmacists towards AMS. Majority of them ( $>90 \%)$ strong agreed/agreed that AMS would reduce inappropriate antibiotic use and antimicrobial resistance, and improve clinical outcomes. However, fewer (76.5\%) respondents strongly agreed/agreed that AMS would reduce healthcare cost. Most of the respondents agreed/strongly agreed that the barriers to community pharmacist's involvement in AMS include lack of training in AMS (56.1\%), lack of cooperation from physicians $(61.2 \%)$ and lack of access to patient's records (66.8\%). In addition, more than half of the respondents disagreed/strongly disagreed with lack of time $(52.1 \%)$ and lack of awareness about antibiotic resistance $(66.3 \%)$ as barriers to their participation in AMS. An overwhelming majority agreed/strongly agreed that boosting public image of community pharmacy services, collaboration with physicians and enhance job satisfaction motivated them to participate in AMS. Overall, the community pharmacists demonstrated positive perceptions towards AMS (median score: 4.0, IQR: 3-5).

Antimicrobial stewardship practices among the community pharmacists

Approximately $97 \%$ of the respondent's dispensed antibiotics without prescription; $60.2 \%$ and $22.4 \%$ 'occasionally' and 'often' dispensed antibiotics without prescription, respectively. More than half of the respondents asked patients about the history of allergy before dispensing prescribed antibiotics. In addition, 30.6\%, 18.4\% and $20.4 \%$ indicated that they contacted the prescriber if the patient 
is allergic to prescribed antibiotics 'occasionally,' 'often' and 'always' respectively. Community pharmacists contacted the physician occasionally (32.7\%), often (23.5\%) and always (18.4\%) when the prescribed antibiotic is inappropriate and also when the prescribed antibiotics involve a drug interaction; $30.6 \%, 27.6 \%$ and $21.4 \%$, respectively. Approximately one-third and one-fifth of the respondents 'occasional' and 'often' substitute prescribed antibiotics when the prescription is suboptimal, respectively. The community pharmacists occasionally $(16.3 \%$ and 14.3$)$, often $(26.5 \%$ and $29.6 \%$ ) and always (48\% and 49\%) informed patients about the potential side effects of prescribed antibiotics (and what they should do when they experience the side effects), respectively. Overall, the median score for AMS practice was 3.5 (1-5). Table 3 summarizes the AMS practices of community pharmacists regarding AMS.

Table 2: Community pharmacist's perceptions towards antimicrobial stewardship program

\begin{tabular}{|c|c|c|c|c|c|c|}
\hline \multirow[t]{2}{*}{ Variable } & \multicolumn{5}{|l|}{ Frequency (\%) } & \multirow{2}{*}{$\begin{array}{l}\text { Median } \\
\text { (IQR) }\end{array}$} \\
\hline & Strongly agree & Agree & Neutral & Disagree & $\begin{array}{l}\text { Strongly } \\
\text { disagree }\end{array}$ & \\
\hline \multicolumn{7}{|l|}{ Perceived importance of AMS } \\
\hline AMS will reduce inappropriate use of antibiotics* & $60(61.2)$ & $32(32.7)$ & $3(3.1)$ & $0(0.0)$ & $1(1.0)$ & $5(1-5)$ \\
\hline AMS will improve patient's clinical outcomes* & $64(65.3)$ & $31(31.6)$ & $1(1.0)$ & $0(0.0)$ & $0(0.0)$ & $5(3-5)$ \\
\hline AMS will reduce healthcare cost* & $36(36.7)$ & $39(39.8)$ & $18(18.4)$ & $3(3.1)$ & $0(0.0)$ & $4(2-5)$ \\
\hline AMS will reduce antimicrobial resistance* & $68(69.4)$ & $25(25.5)$ & $3(3.1)$ & $0(0.0)$ & $0(0.0)$ & $5(3-5)$ \\
\hline Overall score for perceived importance of AMS & & & & & & $5(3-5)$ \\
\hline \multicolumn{7}{|l|}{ Perceived barrier to participation in AMS } \\
\hline Lack of awareness about antibiotic resistance ${ }^{*}$ & $10(10.2)$ & $12(12.2)$ & $7(7.1)$ & $41(41.8)$ & $24(24.5)$ & $4(1-5)$ \\
\hline Lack of training in $\mathrm{AMS}^{*}$ & $12(12.2)$ & $43(43.9)$ & $11(11.2)$ & $22(22.4)$ & $5(5.1)$ & $2(1-5)$ \\
\hline Lack of cooperation from physicians ${ }^{*}$ & $26(26.5)$ & $34(34.7)$ & $19(19.4)$ & $13(13.3)$ & $3(3.1)$ & $2(1-5)$ \\
\hline Lack of reimbursement for AMS services* & $18(18.4)$ & $30(30.6)$ & $22(22.4)$ & $18(18.4)$ & $6(6.1)$ & $2(1-5)$ \\
\hline Lack of access to patient's records* & $28(28.6)$ & 37 (37.8) & $11(11.2)$ & $16(16.3)$ & $3(3.1)$ & $2(1-5)$ \\
\hline Lack of time ${ }^{*}$ & $8(8.2)$ & $16(16.3)$ & $19(19.4)$ & $32(32.7)$ & $19(19.4)$ & $4(1-5)$ \\
\hline Overall score for perceived barriers & & & & & & $2.5(1-5)$ \\
\hline \multicolumn{7}{|l|}{ Perceived motivation } \\
\hline $\begin{array}{l}\text { AMS will boost public confidence in community } \\
\text { pharmacy services }{ }^{*}\end{array}$ & $56(57.1)$ & $40(40.8)$ & $0(0.0)$ & $0(0.0)$ & $0(0.0)$ & $5(4-5)$ \\
\hline AMS will promote collaboration with physicians* & $42(42.9)$ & $46(46.9)$ & $8(8.2)$ & $0(0.0)$ & $0(0.0)$ & $4(3-5)$ \\
\hline AMS will enhance the job satisfaction of pharmacist* & $51(52.0)$ & $40(40.8)$ & $4(4.1)$ & $1(1.0)$ & $0(0.0)$ & $5(2-5)$ \\
\hline Overall score for motivation & & & & & & $4.5(3-5)$ \\
\hline
\end{tabular}

* indicates missing data

Table 3: Antimicrobial stewardship practices of the community pharmacists who participated in the study

\begin{tabular}{|c|c|c|c|c|c|c|}
\hline \multirow[t]{2}{*}{ Variable } & \multicolumn{5}{|c|}{ Frequency (\%) } & \multirow{2}{*}{$\begin{array}{l}\text { Median } \\
\text { (IQR) }\end{array}$} \\
\hline & Never & Rarely & Occasionally & Often & Always & \\
\hline I dispense antibiotics without prescription* & $3(3.1)$ & $9(9.2)$ & $59(60.2)$ & $22(22.4)$ & $1(1.0)$ & $3(1-5)$ \\
\hline $\begin{array}{l}\text { I advise patients to use OTC/self-care treatment when they } \\
\text { present with symptoms of infection that does not need antibiotics* }\end{array}$ & $\begin{array}{l}24 \\
(24.5)\end{array}$ & $15(15.3)$ & $14(14.3)$ & $22(22.4)$ & $\begin{array}{l}18 \\
(18.4)\end{array}$ & $3(1-5)$ \\
\hline $\begin{array}{l}\text { I refer patients to a physician when symptoms are suggestive of an } \\
\text { infection* }\end{array}$ & $5(5.1)$ & $10(10.2)$ & $40(40.8)$ & $19(19.4)$ & $\begin{array}{l}20 \\
(20.4)\end{array}$ & $3(1-5)$ \\
\hline I ask patients about history of allergy before I dispense antibiotics* & $1(1.0)$ & $7(7.1)$ & $9(9.2)$ & $26(26.5)$ & $\begin{array}{l}53 \\
(54.1)\end{array}$ & $5(1-5)$ \\
\hline $\begin{array}{l}\text { I contact the prescriber if the patient is allergic to the prescribed } \\
\text { antibiotics }\end{array}$ & $7(7.1)$ & $19(19.4)$ & $30(30.6)$ & $18(18.4)$ & $\begin{array}{l}20 \\
(20.4)\end{array}$ & $3(1-5)$ \\
\hline I contact the prescriber if the choice of antibiotics is inappropriate ${ }^{*}$ & $4(4.1)$ & 17 (17.3) & $32(32.7)$ & $23(23.5)$ & $\begin{array}{l}18 \\
(18.4)\end{array}$ & $3(1-5)$ \\
\hline $\begin{array}{l}\text { I dispense another antibiotic if the prescribed antibiotic is not } \\
\text { appropriate }^{*}\end{array}$ & $\begin{array}{l}14 \\
(14.3)\end{array}$ & $16(16.3)$ & $32(32.7)$ & $20(20.4)$ & $\begin{array}{l}10 \\
(10.2)\end{array}$ & $3(1-5)$ \\
\hline $\begin{array}{l}\text { I contact the prescriber if the prescribed antibiotics involve a drug } \\
\text { interaction* }\end{array}$ & $5(5.1)$ & $11(11.2)$ & $30(30.6)$ & 27 (27.6) & $\begin{array}{l}21 \\
(21.4)\end{array}$ & $4(1-5)$ \\
\hline $\begin{array}{l}\text { I contact the prescriber if the antibiotic dose/frequency is too high } \\
\text { or too low }{ }^{*}\end{array}$ & $7(7.1)$ & $12(12.2)$ & 27 (27.6) & $22(22.4)$ & $\begin{array}{l}25 \\
(25.5)\end{array}$ & $4(1-5)$ \\
\hline $\begin{array}{l}\text { I adjust dose/frequency of antibiotics without contacting the } \\
\text { prescriber if the prescription is suboptimal/too high* }\end{array}$ & $\begin{array}{l}10 \\
(10.2)\end{array}$ & 19 (19.4) & $18(18.4)$ & $26(26.5)$ & $\begin{array}{l}20 \\
(20.4)\end{array}$ & $3(1-5)$ \\
\hline $\begin{array}{l}\text { I educate patients about expected side effects of prescribed } \\
\text { antibiotics* }^{*}\end{array}$ & $4(4.1)$ & $2(2.0)$ & $16(16.3)$ & $26(26.5)$ & $\begin{array}{l}47 \\
(48.0)\end{array}$ & $4(1-5)$ \\
\hline $\begin{array}{l}\text { I educate patients about what they should do if he/she experience } \\
\text { side effect }\end{array}$ & $2(2.0)$ & $3(3.1)$ & $14(14.3)$ & 29 (29.6) & $\begin{array}{l}48 \\
(49.0)\end{array}$ & $4.5(1-5)$ \\
\hline
\end{tabular}

*indicates missing data

Factors associated with community pharmacist's perceptions regarding antimicrobial stewardship program

The perception that AMS would reduce antimicrobial resistance varied significantly based on number of years of work experience; median score (IQR) for community pharmacists with less than $5 \mathrm{y}$ was lower
(5.0 [3-5]) than those who had more than 5 y work experience $(5.0$ (4-5); $\mathrm{P}=0.026$. Those who had more than 5 y working experience had higher score (2.5 [1-5]) for the item "lack of training is a barrier to community pharmacists' participation in AMS" than those who had less than 5 y working experience (2.0, [1-5]), P 0.023. Similarly, pharmacy owners had significantly higher score $3.0(1-5)$ compared 
to pharmacy managers; 2.0 (1-5), and staff pharmacists; 2.0 (1-5) for the same item described above. Overall, pharmacy owners $(3.0,1-5)$ had significantly higher positive perception toward barriers that limit community pharmacists involvement in AMS compared to pharmacy managers $(2.75,1-4)$ and staff pharmacists $(2.25,1-4)$. Table 4 shows the factors associated with respondent's perception towards AMS program.

Factors associated with community pharmacist's practices of antimicrobial stewardship

Pharmacy managers had higher score for the item "I refer patients to a physician when symptoms are suggestive of an infection" (4.5, $1-5)$ than pharmacy owners $(3.0,1-5)$ and staff pharmacists $(3.0$, 1-5); $\mathrm{P}=0.032$. Those who never/rarely dispensed antibiotics without prescription had significantly lower score for the item "I educate patients about expected side effects of prescribed antibiotics" $(4.0,1-5)$ than those who occasionally/often/always dispensed antibiotic without prescription (5.0, 1-5). In addition, pharmacy managers had the highest score for the same item (5.0, 35) compared to pharmacy owners and staff pharmacists (4.0, 1-5), P $=0.019$. Pharmacy managers had significantly higher score for patient education regarding what they should do when they experience side effects $(5.0,3-5)$ compared to pharmacy owners and staff pharmacists $(4.0,1-5)$. Overall, those who never/rarely dispensed antibiotics without prescription had significantly lower practice score $(3.0,2-5)$ compared to those who occasionally/often/always dispensed antibiotics without prescription $(4.0,1-5)$. Staff pharmacists had significantly lower practice score $(3.0,1.5-5)$ compared to pharmacy owners $(4.0,3-5)$ and pharmacy managers $(4.0,1-5) ; \mathrm{P}=0.028$. Community pharmacy owner and manager (4.0,1-5 and 4.0,3-5, respectively) had significantly higher practice score than staff pharmacist (3.0, 1.5-5).

Table 4 summarizes the factors associated with AMS practices of the community pharmacists who participated in the study.

Table 4: Factors associated with respondent's practices and perceptions regarding antimicrobial stewardship

\begin{tabular}{|c|c|c|c|c|c|c|}
\hline \multirow[t]{2}{*}{ Variable } & \multicolumn{6}{|c|}{ P value } \\
\hline & Age & Gender & Qualification $^{\#}$ & $\begin{array}{l}\text { Job } \\
\text { status }\end{array}$ & $\begin{array}{l}\text { Working } \\
\text { experience }\end{array}$ & $\begin{array}{l}\text { Dispense antibiotics } \\
\text { without prescription }^{\S}\end{array}$ \\
\hline \multicolumn{7}{|l|}{ Perceived importance of AMS } \\
\hline AMS will reduce inappropriate use of antibiotics & 0.465 & 0.424 & 0.644 & 0.667 & 0.607 & 0.914 \\
\hline AMS will improve patient's clinical outcomes & 0.089 & 0.266 & 0.371 & 0.443 & 0.308 & 0.650 \\
\hline AMS will reduce healthcare cost & 0.948 & 0.189 & 0.893 & 0.650 & 0.770 & 0.866 \\
\hline AMS will reduce antimicrobial resistance & 0.045 & 1.000 & 0.167 & 0.986 & 0.026 & 0.589 \\
\hline Overall score for perceived importance of AMS & 0.112 & 0.244 & 0.278 & 0.801 & 0.127 & 0.414 \\
\hline \multicolumn{7}{|l|}{ Perceived barrier to participation in AMS } \\
\hline Lack of awareness about antibiotic resistance & 0.153 & 0.942 & 0.116 & 0.723 & 0.841 & 0.428 \\
\hline Lack of training in AMS & 0.001 & 0.979 & 0.799 & 0.003 & 0.023 & 0.080 \\
\hline Lack of cooperation from physicians & 0.275 & 0.640 & 0.590 & 0.274 & 0.233 & 0.127 \\
\hline Lack of reimbursement for AMS services & 0.340 & 0.164 & 0.255 & 0.213 & 0.656 & 0.627 \\
\hline Lack of access to patient's records & 0.521 & 0.197 & 0.961 & 0.113 & 0.314 & 0.947 \\
\hline Lack of time & 0.025 & 0.149 & 0.569 & 0.379 & 0.114 & 0.809 \\
\hline $\begin{array}{l}\text { Overall score for perceived barriers to participation } \\
\text { in AMS }\end{array}$ & 0.019 & 0.254 & 0.329 & 0.030 & 0.174 & 0.155 \\
\hline \multicolumn{7}{|l|}{ Perceived motivation } \\
\hline $\begin{array}{l}\text { AMS will boost public confidence in community } \\
\text { pharmacy services }\end{array}$ & 0.700 & 0.643 & 0.949 & 0.614 & 0.571 & 0.793 \\
\hline AMS will promote collaboration with physicians & 0.357 & 0.596 & 0.692 & 0.114 & 0.171 & 0.549 \\
\hline AMS will enhance the job satisfaction of pharmacist & 0.352 & 0.639 & 0.912 & 0.516 & 0.151 & 0.960 \\
\hline Overall score for perceived motivation & 0.475 & 0.673 & 0.777 & 0.511 & 0.307 & 0.729 \\
\hline Overall score for perception towards AMS & 0.531 & 0.913 & 0.902 & 0.855 & 0.967 & 0.770 \\
\hline \multicolumn{7}{|l|}{ Antimicrobial stewardship practices } \\
\hline I dispense antimicrobial without prescription & 0.062 & 0.247 & 0.401 & 0.042 & 0.071 & - \\
\hline $\begin{array}{l}\text { I advise patients to use OTC/self-care treatment when } \\
\text { they present with symptoms of infection that does not } \\
\text { need antibiotics }\end{array}$ & 0.911 & 0.973 & 0.205 & 0.823 & 0.717 & 0.415 \\
\hline $\begin{array}{l}\text { I refer patients to a physician when symptoms are } \\
\text { suggestive of an infection }\end{array}$ & 0.005 & 0.911 & 0.186 & 0.032 & 0.365 & 0.037 \\
\hline $\begin{array}{l}\text { I ask patients about history of allergy before I } \\
\text { dispense antibiotics }\end{array}$ & 0.932 & 0.737 & 0.600 & 0.088 & 0.733 & 0.048 \\
\hline $\begin{array}{l}\text { I contact the prescriber if the patient is allergic to the } \\
\text { prescribed antibiotics }\end{array}$ & 0.832 & 0.721 & 0.784 & 0.279 & 0.819 & 0.577 \\
\hline $\begin{array}{l}\text { I contact the prescriber if the choice of antibiotics is } \\
\text { inappropriate }\end{array}$ & 0.576 & 0.636 & 0.284 & 0.291 & 0.341 & 0.582 \\
\hline $\begin{array}{l}\text { I dispense another antibiotic if the prescribed } \\
\text { antibiotic is not optimal }\end{array}$ & 0.547 & 0.037 & 0.036 & 0.174 & 0.247 & 0.366 \\
\hline $\begin{array}{l}\text { I contact the prescriber if the prescribed antibiotics } \\
\text { involve a drug interaction }\end{array}$ & 0.120 & 0.427 & 0.452 & 0.347 & 0.273 & 0.223 \\
\hline $\begin{array}{l}\text { I contact the prescriber if the antibiotic } \\
\text { dose/frequency is too high or too low }\end{array}$ & 0.566 & 0.565 & 0.686 & 0.760 & 0.218 & 0.892 \\
\hline $\begin{array}{l}\text { I adjust dose/frequency of antibiotics without } \\
\text { contacting the prescriber if the prescription is } \\
\text { suboptimal/too high }\end{array}$ & 0.724 & 0.969 & 0.704 & 0.072 & 0.139 & 0.016 \\
\hline $\begin{array}{l}\text { I educate patients about expected side effects of } \\
\text { prescribed antibiotics }\end{array}$ & 0.552 & 0.386 & 0.245 & 0.007 & 0.253 & 0.019 \\
\hline $\begin{array}{l}\text { I educate patients about what they should do if he/she } \\
\text { experience side effect }\end{array}$ & 0.387 & 0.887 & 0.328 & 0.011 & 0.057 & 0.314 \\
\hline Overall median practice score & 0.182 & 0.151 & 0.718 & 0.028 & 0.538 & 0.009 \\
\hline
\end{tabular}

Note: *comparison between less than $5 \mathrm{y}$ and more than $5 \mathrm{y}$ working experience, " comparison between postgraduate and no postgraduate,

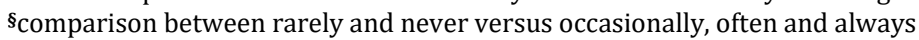




\section{DISCUSSION}

Community pharmacists have an important role to play in promoting rational use of antibiotics. Overall, the current study found that community pharmacists had positive perceptions and good AMS practices. The current study revealed that most community pharmacists had positive perceptions towards the goals of AMS and the motivations to participate in the program. These observations were consistent with the findings of previous studies $[13,16-18]$. The current study also found that lack of access to patient's records, lack of support from prescribers and lack of training in AMS were the major barriers that hinder community pharmacist's participation in AMS activities and these were corroborated by a previous study [13]. Currently there is no institution that offers formal training in AMS in Nigeria and this explains the lack of training among community pharmacists, similar to a previous report among hospital pharmacists [14]. AMS training has not been incorporated into undergraduate pharmacy curriculum in some developing countries and this would affects the competence and confidence of pharmacists to participate in AMS activities [19]. Therefore, policy-makers should encourage pharmacy training institutions to develop and deliver AMS contents in undergraduate and postgraduate programs. Meanwhile, workshops and seminars should be organized for community pharmacists to improve their AMS skills and competence.

Inter-professional conflict between healthcare professionals has been reported in Nigeria and it affects the quality of patient care [20]. The lack of cooperation from prescribers was identified by community pharmacists as a barrier to their involvement in AMS activities in the current study. Currently, there are ongoing efforts by professional organizations/societies to harmonize healthcare professionals in the country. It is important for the stakeholders to extend these efforts to community pharmacy to promote collaboration and improve the quality of patient care. Nonprescription dispensing contributes to the inappropriate use of antibiotics in the community; antibiotics are commonly used for illnesses that are self-limiting [5]. The current study found that most community pharmacists dispensed antibiotics without prescription and this was in agreement with the results of previous studies conducted in developing countries $[16,18]$. Regulatory authorities should design and implement strategies to reduce non-prescription dispensing of antibiotics by community pharmacists and this should include public awareness regarding the dangers of self-medication.

Currently, there is no formal AMS policy/guideline for community pharmacists in Nigeria. However, most of them asked patients about allergy to antibiotics, and educated patients about the potential side effects of antibiotics and how to the side effects when they occur, and these were similar to previous studies [13, 16-18]. This implies that community pharmacists practice AMS despite the lack of a formal program and could be attributed to the integration of pharmaceutical care, which bears similitude to AMS, into community pharmacy practice. Collaboration between prescribers and community pharmacists is crucial for the success of AMS in the community setting and the current study revealed that most community pharmacists contacted prescribers when they identify potential drug therapy issues including allergy, interaction and inappropriate choice and dosing. These practices would promote rational use of antibiotics and improve the quality of care provided by community pharmacists. The result also revealed that some community pharmacists substituted prescribed antibiotics and adjusted the dose and frequency without the consent of the prescriber. These attitudes could be attributed to lack of collaboration and misunderstanding between the prescribers and the community pharmacists. In addition, community pharmacists may succumb to patient's pressure/request to use their discretion to alter antibiotic prescription. These malpractices should be discouraged and community pharmacists should be advised to adhere to dispensing guidelines.

The current study revealed that dispensing antibiotics without prescription and job status were factors that influenced overall AMS practices among community pharmacists. This was inconsistent with previous studies [16-18]. The inconsistencies could be explained by the differences in the demographic and professional characteristics of the respondents. Also, community pharmacists' demographic and professional characteristics did not influenced the overall perception towards AMS in the current study as against previous findings [16-18]. However, the present study found that respondent's age and job status affected the perceived barriers towards AMS among community pharmacists. Future studies should explore the association between job status and practices and perceptions towards AMS.

The limitations of the currents study includes small sample size and the use of snowball sampling technique. There is a possibility for exclusion of community pharmacists practicing in secluded areas, however, an exhaustive sampling was done to cover all available community pharmacies in the cities. In addition, the study was conducted in urban areas and may not reflect the perceptions and practices of community pharmacists in non-urban settings. Furthermore, the findings cannot be generalized for community pharmacists in Nigeria. The results should be interpreted with caution because of the influence of social desirability bias on the responses provided by the community pharmacists.

\section{CONCLUSION}

Community pharmacists in this study demonstrated positive perceptions and good antimicrobial stewardship practices. Lack of access to patient's records, lack of support from prescribers and lack of training in AMS were identified as major barriers to community pharmacist's involvement in AMS activities. Job status and dispensing antibiotics without prescription were factors that influenced AMS practices among community pharmacists.

\section{ACKNOWLEDGEMENT}

The author wishes to thank all the community pharmacists that participated in the survey. Special thanks to Isah Hauwa Kulu and Isah Jibrin who helped with the distribution and retrieval of the questionnaires.

\section{AUTHORS CONTRIBUTIONS}

Abubakar Usman conceived the idea, developed the proposal, collected, analyzed and interpreted the data, and wrote the manuscript.

\section{CONFLICTS OF INTERESTS}

Declared none

\section{REFERENCES}

1. World Health Organization. Antimicrobial resistance: global report on surveillance. World Health Organization; 2014.

2. US Department of Health and Human Services. Antibiotic resistance threats in the United States. Centers for Disease Control and Prevention; 2013. Available from: https://www.cdc.gov/drugresistance/pdf/ar-threats-2013508.pdf. [Last accessed on 24 Sep 2018].

3. European Centre for Disease Prevention and Control and European Medicines Agency. The Bacterial Challenge: Time to React-A Call to Narrow the Gap Between Multidrug-Resistant Bacteria in the EU and the Development of New Antibacterial Agents. ECDC/EMEA Joint Technical report; 2009. Available from: https:// ecdc.europa.eu/sites/portal/files/media/en/publications/Publicat ions/0909_TER_The_Bacterial_Challenge_Time_to_React.pdf. [Last accessed on 25 Sep 2018].

4. Morgan DJ, Okeke IN, Laxminarayan R, Perencevich EN, Weisenberg S. Non-prescription antimicrobial use worldwide: a systematic review. Lancet Infect Dis 2011;11:692-701.

5. Auta A, Hadi MA, Oga E, Adewuyi EO, Abdu-Aguye SN, Adeloye $D$, et al. Global access to antibiotics without prescription in community pharmacies: a systematic review and metaanalysis. J Infect 2019;78:8-18.

6. Abubakar U. Antibiotic use among hospitalized patients in northern Nigeria: a multicenter point-prevalence survey. BMC Infect Dis 2020;20:86.

7. Abubakar U, Sulaiman SS, Adesiyun AG. Utilization of surgical antibiotic prophylaxis for obstetrics and gynaecology surgeries in Northern Nigeria. Int J Clin Pharm 2018;40:1037-43. 
8. Esimone CO, Nworu CS, Udeogaranya OP. Utilization of antimicrobial agents with and without prescription by outpatients in selected pharmacies in South-eastern Nigeria. Pharm World Sci 2007;29:655-60.

9. Abubakar U, Sulaiman SA. Prevalence, trend and antimicrobial susceptibility of Methicillin Resistant Staphylococcus aureus in Nigeria: a systematic review. J Infect Public Health 2018;11:763-70.

10. Badger Emeka LI, Emeka PM, Okosi M. Evaluation of the extent and reasons for increased non-prescription antibiotics use in a University town, Nsukka Nigeria. Int J Health Sci 2018;12:11.

11. Sapkota AR, Coker ME, Goldstein RER, Atkinson NL, Sweet SJ, Sopeju PO, et al. Self-medication with antibiotics for the treatment of menstrual symptoms in southwest Nigeria: a cross-sectional study. BMC Public Health 2010;10:610.

12. Olayemi OJ, Olayinka BO, Musa AI. Evaluation of antibiotic selfmedication pattern amongst undergraduate students of Ahmadu Bello University (Main Campus) Zaria. Res J Appl Sci Eng Technol 2010;2:35-8.

13. Rizvi T, Thompson A, Williams M, Zaidi STR. Perceptions and current practices of community pharmacists regarding antimicrobial stewardship in Tasmania. Int J Clin Pharm 2018;40:1380-7.

14. Abubakar U, B Tangiisuran. Nationwide survey of Pharmacist's involvement in antimicrobial stewardship program in Nigerian Tertiary Hospitals. J Glob Antimicrob Resist 2019. Doi.org/ 10.1016/J.Jgar.2019.10.007.
15. Abubakar U, Sulaiman SAS, Adesiyun AG. Impact of pharmacistled antibiotic stewardship interventions on compliance with surgical antibiotic prophylaxis in obstetric and gynecologic surgeries in Nigeria. PloS One 2019:14:e0213395.

16. Erku DA. Antimicrobial stewardship: a cross-sectional survey assessing the perceptions and practices of community pharmacists in Ethiopia. Interdiscip Perspect Infect Dis 2016. DOI: $10.1155 / 2016 / 5686752$.

17. Khan MU, Hassali MAA, Ahmad A, Elkalmi RM, Zaidi STR, Dhingra S. Perceptions and practices of community pharmacists towards antimicrobial stewardship in the state of Selangor, Malaysia. PloS One 2016;11:e0149623.

18. Sarwar MR, Saqib A, Iftikhar S, Sadiq T. Knowledge of community pharmacists about antibiotics, and their perceptions and practices regarding antimicrobial stewardship: a cross-sectional study in Punjab, Pakistan. Infect Drug Resist 2018;11:133.

19. Abubakar U, Muhammad HT, Sulaiman SA, Ramatillah DL, Amir 0 . Knowledge and self-confidence of antibiotic resistance, appropriate antibiotic therapy, and antibiotic stewardship among pharmacy undergraduate students in three Asian countries. Curr Pharm Teach Learn 2020. Doi.org/ 10.1016/J.Cptl.2019.12.002.

20. Onyekwere LA. Inter-professional collaboration and work efficiency in secondary healthcare delivery system in rivers state. Int J Sci Res Educ 2013;6:9-46. 